\title{
Congresso Ibero-Americano em Investigação Qualitativa - CIAIQ: socializando e construindo conhecimento
}

\author{
Zélia Maria de Sousa Araújo Santos', Sílvia Tonhom², Catarina Brandão³ \\ 'Universidade de Fortaleza. Fortaleza, Ceará, Brasil. ORCID: 0000-0002-5824-0723. zeliasantos@unifor.br \\ ${ }^{2}$ Faculdade de Medicina de Marília. Maraília, São Paulo, Brasil. ORCID: 0000-0001-7522-2861. siltonhom@gmail.com \\ ${ }^{3}$ Autora para correspondência. Faculdade de Psicologia e de Ciências da Educação da Universidade do Porto. Porto, \\ Portugal. ORCID 0000-0002-4305-5605. catarina@fpce.up.pt
}

O Congresso Ibero-Americano em Investigação Qualitativa (CIAIQ) é um evento que acontece anualmente, reunindo representantes da comunidade científica internacional que estudam e pesquisam nesta abordagem de investigação. Cada evento traz em seu bojo um diferencial que atrai cada vez mais participantes que se destacam pelo compromisso com a excelência no âmbito da investigação qualitativa.

Evento científico é uma atividade que objetiva: reunir especialistas e interessados em determinadas áreas do conhecimento para discussão de temáticas que atendam a inquietações comuns, com vistas à atualização e ao progresso da pesquisa científica; divulgar resultados de pesquisa de pesquisadores e de estudantes de graduação e de pós-graduação, e colocá-los em debate com vistas a sua qualificação e validação no âmbito da comunidade científica; incentivar o desenvolvimento de campos de pesquisa ainda emergentes; e promover a capacitação de pesquisadores e formação de futuros pesquisadores. Ao mesmo tempo, permite o desenvolvimento de novas redes de investigação, muitas vezes internacionais, permitindo que investigadores saiam dos contextos de trabalhos institucionais e contactem com os pares de diversas origens.
Para Figueredo, Aquino, Andrade e Rosas (2016), os eventos científicos ou encontros científicos apresentam-se como fonte essencial na busca de novos conhecimentos, permitindo o enriquecimento do saber acadêmico, uma vez que reúnem profissionais especialistas, estudantes e outros grupos com interesses e áreas em comum, para trocas e transmissão de informações, ampliando e construindo assim, sua cultura, formação acadêmica e profissional. Logo, as principais funções destes eventos são o compartilhamento de experiências entre os participantes do evento; o acesso a informações atualizadas sobre os progressos recentes de uma área profissional ou de estudo; a divulgação de novos conhecimentos e o planejamento de metas para o futuro.

Percebe-se, assim, como é relevante a participação discente (graduação e pós-graduação) em eventos científicos, para o contato com a comunidade, troca de experiências, estabelecimento de colaborações e intercâmbios, ajustes no desenvolvimento do projeto de pesquisa, dentre outros fatores.

No CIAIQ há a integração de instituições de ensino, de investigação e de serviços, cujos participantes buscam soluções para as suas inquietações 
por meio da pesquisa qualitativa, e se comprometem com a devolutiva dos resultados por meio da divulgação em evento científico desse porte.

O CIAIQ disponibiliza e incentiva a submissão de artigos científicos nos diversos campos de aplicação na Investigação Qualitativa, desde a Educação à Saúde, Ciências Sociais, Engenharia e Tecnologia, entre outras, bem como uma visão transversal e holística, com a abordagem de diversas temáticas e dimensões da investigação (CIAIQ, 2018).

A submissão dos trabalhos envolve vários campos e em várias áreas: Investigação Qualitativa na Educação - Ensino Superior, Ensino básico, Avaliação, Currículo, Didáticas, Ensino de Ciências, Línguas, História, Tecnologia, etc; Investigação Qualitativa na Saúde - Medicina, Enfermagem, Geriatria, Gerontologia, Psicologia, etc; Investigação Qualitativa nas Ciências Sociais - Comunicação, Artes, Linguística, Sociologia, Antropologia, Psicologia das Organizações e do Trabalho, Administração, Marketing, Gestão e Economia, Ciência Política, etc; Investigação Qualitativa na Engenharia e Tecnologia - metodologias de suporte baseadas em computador e no software para investigação qualitativa e na investigação qualitativa nas áreas da Engenharia e Tecnologia, Sistemas de Informação e Educação em Engenharia (CIAIQ, 2018).
As temáticas se constituem de fundamentais e operacionais. Nas primeiras integram-se: Fundamentação e Paradigmas de Investigação Qualitativa; Sistematização de estudos com Abordagens Qualitativas; Investigação Qualitativa e Métodos Mistos. E nas segundas encontram-se: tipologias de Análise de Dados; Processos inovadores de Análise Qualitativa de Dados; Investigação Qualitativa em Contexto Web; e Análise Qualitativa com Apoio de Software Específico (CIAIQ, 2018).

Para a concretização do evento, são necessários os trabalhos de várias comissões que atuam de modo articulado: Comissão Coordenadora, Comissão Consultiva, Comissão Organizadora local, e Comissão Científica.

Os trabalhos são submetidos no formato de Painéis de Investigação (dedicados a grupos de investigação que apresentam o trabalho que têm vindo a desenvolver), Workshops (oficinas de partilha de métodos e técnicas) e Comunicações, que podem ser no formato presencial ou em vídeo (on line) (CIAIQ, 2018). Todos estes trabalhos são sujeitos a um processo de blind review, assumido pela Comissão Científica do evento. Para essa avaliação dos trabalhos, a Comissão Científica se utiliza de Critérios de Avaliação, previamente estruturados e aprovados por essa comissão, conforme está descrito no Quadro 1 (CIAIQ, 2018):

Quadro 1. Critérios e Questões Orientadoras para Comissão Científica do CIAIQ (continua)

\begin{tabular}{|l|l|l|}
\hline $\begin{array}{l}\text { Estrutura do } \\
\text { artigo }\end{array}$ & Questões Orientadoras & Orientações Gerais \\
\hline $\begin{array}{l}\text { Questões e } \\
\text { Investigação }\end{array}$ & $\begin{array}{l}\text { 1-Existe a inclusão de questões } \\
\text { relacionadas com as temáticas } \\
\text { do Congresso, nomeadamente a } \\
\text { metodologia de investigação } \\
\text { qualitativa? }\end{array}$ & $\begin{array}{l}\text { Quais são as temáticas do congresso? Onde se encaixa o seu } \\
\text { artigo diretamente? O seu artigo é transversal a mais de uma } \\
\text { temática? Quais? Existe no título, resumo ou na introdução uma } \\
\text { indicação clara das problemáticas metodológicas, técnicas e } \\
\text { ferramentas utilizadas na investigação qualitativa? }\end{array}$ \\
$\begin{array}{l}\text { 2-As questões de investigação } \\
\text { estão claramente formuladas? }\end{array}$ & $\begin{array}{l}\text { As questões de investigação têm destaque e são claras? Existe } \\
\text { um sistema hierárquico de questões e/ou sub-questões de } \\
\text { investigação? }\end{array}$ \\
$\begin{array}{l}\text { 3-A fundamentação teórica é } \\
\text { atualizada e articulada com o } \\
\text { tema ou objetivos do estudo? }\end{array}$ & $\begin{array}{l}\text { Quantos autores internacionais são citados como base do } \\
\text { trabalho? As publicações “clássicas" são citadas de forma } \\
\text { articulada com outras publicações (por exemplo, últimos 5 anos)? }\end{array}$ \\
\hline
\end{tabular}


Quadro 1. Critérios e Questões Orientadoras para Comissão Científica do CIAIQ (conclusão)

\begin{tabular}{|c|c|c|}
\hline $\begin{array}{l}\text { Estrutura do } \\
\text { artigo }\end{array}$ & Questões Orientadoras & Orientações Gerais \\
\hline Metodologia & $\begin{array}{l}\text { 4-A opção metodológica é } \\
\text { coerente com o problema e as } \\
\text { questões de investigação? } \\
\text { 5-A recolha de dados está } \\
\text { descrita de forma clara (i.e. } \\
\text { informação sobre a } \\
\text { disponibilidade ou origem dos } \\
\text { dados)? } \\
\text { 6-Os métodos e técnicas de } \\
\text { análise de dados são adequados } \\
\text { ao estudo? } \\
\text { 7-É explicado o processo de } \\
\text { codificação (i.e. número de } \\
\text { investigadores envolvidos, } \\
\text { dimensões, categorias de } \\
\text { análise)? }\end{array}$ & $\begin{array}{l}\text { Todas as questões de investigação enunciadas são contempladas } \\
\text { no desenho metodológico? É fácil perceber a sua coerência? } \\
\text { Existe alguma tabela ou figura que explicite a sua relação? } \\
\text { Quais os dados que serviram de base para a construção de } \\
\text { respostas às questões de investigação? Existem justificações } \\
\text { sobre os processos éticos (autorizações e consentimento } \\
\text { informado dos sujeitos envolvidos)? } \\
\text { Quais os métodos utilizados? As técnicas de análise são } \\
\text { apresentadas? Estão descritos de forma clara? São apresentados } \\
\text { elementos de um sistema de análise, tais como dimensões, } \\
\text { categorias e subcategorias? São coerentes com as questões de } \\
\text { investigação? } \\
\text { Qual o processo e o número de investigadores envolvidos na } \\
\text { codificação? É explicado como foi validada a codificação? Existe a } \\
\text { preocupação em mostrar quão rigoroso e sistemático foi este } \\
\text { processo? }\end{array}$ \\
\hline $\begin{array}{l}\text { Resultados e } \\
\text { Conclusões }\end{array}$ & $\begin{array}{l}\text { 8-A quantidade e qualidade dos } \\
\text { dados apresentados possuem } \\
\text { potencial para uma análise } \\
\text { qualitativa relevante? } \\
\text { 9-A discussão dos resultados } \\
\text { tem por base a fundamentação } \\
\text { teórica e as questões de } \\
\text { investigação apresentadas? } \\
\text { 10-Nas conclusões são } \\
\text { apresentadas sínteses dos } \\
\text { argumentos que dão suporte } \\
\text { aos resultados? } \\
\text { 11-As conclusões oferecem } \\
\text { algum contributo para as } \\
\text { metodologias qualitativas? } \\
\text { 12-Concorda com as } \\
\text { contribuições (implicações, } \\
\text { impacto) para o } \\
\text { desenvolvimento da investigação } \\
\text { qualitativa mencionada pelos } \\
\text { autores? }\end{array}$ & $\begin{array}{l}\text { Os autores indicam que a quantidade e qualidade dos dados são } \\
\text { consistentes e suficientes para responder às questões de } \\
\text { investigação? Existe diversidade de fontes e características de } \\
\text { dados? } \\
\text { Qual o poder de argumentação patente na discussão dos } \\
\text { resultados? Estão articulados com a fundamentação teórica e } \\
\text { com os objetivos e questões de investigação do trabalho? } \\
\text { Existe nas conclusões uma síntese dos resultados? Estas } \\
\text { conclusões estão relacionadas com as questões de investigação? } \\
\text { Existe triangulação das conclusões com a literatura? São } \\
\text { apresentadas as limitações destas conclusões? } \\
\text { Qual a relevância dada à investigação qualitativa nas conclusões? } \\
\text { É possível identificar alguma conclusão direta ou indiretamente } \\
\text { ligada à metodologia qualitativa? } \\
\text { É possível identificar as implicações do processo, resultados e } \\
\text { conclusões do trabalho? É apontado o impacto ou possíveis } \\
\text { impactos do trabalho em diferentes esferas de influência } \\
\text { (formação, investigação, sociedade etc.)? }\end{array}$ \\
\hline
\end{tabular}

Fonte: www.ciaiq.org 
Após a apresentação dos trabalhos no evento, a Comissão Coordenadora solicita a colaboração de integrantes da Comissão Científica para compor e Equipe de Editores Convidados para fins de selecionar artigos que tenham condições teórico-metodológicas para provável publicação em periódicos indexados com elevada qualidade na área que estão associadas com CIAIQ, que seguem (para os trabalhos do CIAIQ 2018): Ámbitos. Revista Internacional de Comunicación; Cadernos de Educação, Tecnologia e Sociedade; Escola Anna Nery Revista de Enfermagem; Index de Enfermería; International Journal of Marketing, Communication and New Media; Millenium - Journal of Education, Technologies and Health; Revista Bahiana de Enfermagem; Revista Brasileira de Enfermagem; Revista Brasileira em Promoção da Saúde; Revista Campo Abierto; Revista Ciência \& Saúde Coletiva; Revista da Escola de Enfermagem da USP; Revista de Pesquisa Qualitativa; Revista Fórum Identidades; Revista Fronteiras; Sociedade, Tecnologia e Meio Ambiente; Revista Ibérica de Sistemas e Tecnologias de Informação; Revista Indagatio Didactica; Revista Lusófona de Educação; Revista Multi-Science; e Revista Psicologia Diversidade e Saúde (CIAIQ, 2018).

Os artigos aprovados são integrados em volumes especiais ou correntes de cada periódico, sendo sempre identificada a sua relação com o CIAIQ. Em qualquer dos casos, os Editores das revistas e os Editores Convidados garantem que os artigos passam por dois procedimentos para fins de publicação ou não no periódico indicado:

1) os artigos são reescritos numa versão estendida daquele publicado nas Atas do CIAIQ2018 (sendo o original citado no texto e na lista final de bibliografia consultada na nova versão), o título e o resumo são alterados e, adicionalmente, altera-se/acrescenta-se pelo menos $50 \%$ do conteúdo do artigo original. $O$ artigo deve ainda ser formatado seguindo as normas da revista.

2) o artigo é reavaliado pelos Editores Convidados ou outros revisores, conforme o instrumento de avaliação do periódico selecionado.

A escrita científica é um gênero específico, empregado pelos pesquisadores, para divulgar o resultado de seus estudos. A linguagem utilizada em textos acadêmicos é formal e técnica. O objetivo de um autor é alcançar o maior número de leitores possível com as suas informações. Por sua vez, o objetivo do leitor é encontrar novidades, em uma leitura rápida e de acesso fácil (Ferraz, 2016).

Ressalta-se que a parceria entre a Revista Psicologia, Diversidade e Saúde (RPDS) e o CIAIQ considera estes desígnios e faz por contribuir na divulgação do saber que vem sendo produzido à luz da pesquisa qualitativa. Orgulha-se pela associação a esta parceria e assume-se o compromisso de continuar a apoiar a qualidade dos trabalhos que daqui derivam.

\section{Referências}

Congresso Ibero-Americano em Investigação Qualitativa. Trabalhos CIAIQ 2018 [Internet]. Recuperado de https:// proceedings.ciaiq.org/index.php/ciaiq2018/issue/archive

Ferraz, É. C., \& Navas, A. L. G, P. (2016). Publicação de artigos científicos: recomendações práticas para jovens pesquisadores. [Internet]. Recuperado de https://www. abecbrasil.org.br/arquivos/recomendacoes publicacao jovens_pesquisadores.pdf

Figueredo, J. L., Aquino, A. F. C., Andrade, E. N., \& Rosas, L. S. (2016). A importância da participação dos estudantes do ensino superior em eventos científicos para sua formação acadêmica. Anais do Congresso Nacional de Educação, Natal, RN, Brasil, 3. Recuperado de https://editorarealize. com.br/revistas/conedu/trabalhos/TRABALHO_EV056 MD4 SA4 ID2844 15082016151347.pdf 